\title{
The role of ventricular assist device in children
}

\author{
Eva Maria Javier Delmo ${ }^{1}$, Mariano Francisco del Maria Javier ${ }^{2}$, Roland Hetzer ${ }^{2}$ \\ ${ }^{1}$ Charité Research Organization, Universitätsmedizin Berlin-Charité, Berlin, Germany; ${ }^{2}$ Department of Cardiothoracic and Vascular Surgery, Cardio \\ Centrum Berlin, Berlin, Germany \\ Contributions: (I) Conception and design: All authors; (II) Provision of study materials or patients: All author; (III) Collection and assembly of data: \\ All authors; (IV) Data analysis and interpretation: All authors; (V) Manuscript writing: All authors; (VI) Final approval of manuscript: All authors. \\ Correspondence to: Eva Maria Javier Delmo, MD, MSc, PhD. Charité-Universitätsmedizin Berlin, Charité Research Organization, Virchowweg 10, \\ 10117 Berlin, Germany. Email: eva.javierdelmo@gmail.com.
}

\begin{abstract}
The first and successful implantation of a ventricular assist device in 1990 has allowed an 8-yearold child with an end-stage heart failure to undergo a heart transplantation. This milestone paved the way to consider support with ventricular assist in the armamentarium of heart failure management in infants, children and adolescents. Several systems have evolved and faded owing to unacceptable complications. Indications and contraindications to implantation have been established. Anticoagulation management is still on its way to impeccability. Despite the challenges, issues and concerns revolving around ventricular assist devices, the system definitely supports pediatric patients with end-stage heart failure until heart transplantation and could allow recovery of the myocardium.
\end{abstract}

Keywords: Congenital heart disease; heart failure (HF); heart transplantation; myocardial recovery; ventricular assist device (VAD)

Submitted Feb 15, 2020. Accepted for publication Apr 21, 2020.

doi: $10.21037 / \mathrm{cdt}-20-282$

View this article at: http://dx.doi.org/10.21037/cdt-20-282

\section{Introduction}

Orthotopic heart transplantation (OHT) is acknowledged as the benchmark in management of end-stage heart failure (HF). An overwhelming concern which then emerged has been the shortage of donor organs. This disparity has been filled up with the evolution of mechanical circulatory support systems which eventually became a great option to improve conditions and survival of patients suffering from advanced HF. While various ventricular assist devices (VAD) are available for the adult population, there is a limited device availability for pediatric application. Nonetheless, VADs in infants, children and adolescents have undergone rapid progress in the last three decades, after the first implantation in an 8-year-old boy on whom an adult VAD was implanted (1). Over time, through pump technological innovations designed according to the patients' anatomical and physiological demands along with improvement of perioperative care especially perfecting the anticoagulation management and the knowledge of timing and indications of implantation, it has been recognized that VADs play a significant role in management of HF in this special group. Various adjustments in clinical judgment and improvement in patient care paved the way to the acceptance of VAD as a long-term support of the failing ventricle.

This report elaborates the contribution of VADs in infants and children with end-stage $\mathrm{HF}$ as bridge to heart transplantation, to status of transplantability and to myocardial recovery. It discusses several important aspects of pediatric VAD, special demands in children and essential issues associated with VAD support in infants, children and adolescents and perspectives.

\section{The ventricular assist devices in children}

The initial clinically available mechanical circulatory support systems were designed for performance and anatomical adaptation to the needs of adults. However, it soon became necessary to develop mechanical circulatory support systems suitable for small patients with a body weight of $\geq 3$ to $30 \mathrm{~kg}$ 
and a correspondingly small cardiac output. The connections to the circulatory system had to be miniaturized requiring new types of valves for pulsatile pumps.

\section{Extracorporeal pulsatile VAD}

\section{EXCOR $^{\circledR}$ (Berlin Heart GmbH, Berlin Germany)}

$\mathrm{EXCOR}^{\circledR}$ was used as the first children's system for bridge to transplantation with a $50 \mathrm{~mL}$ pump in 1990 in Berlin (1). In 1992 an infant system with a $10 \mathrm{~mL}$ pump was implanted in Berlin for the first time (2). EXCOR ${ }^{\circledR}$ has been approved in 2014 for clinical use in the United States.

$\mathrm{EXCOR}^{\circledR}$ is an extracorporeal, pneumatically- driven pulsatile pump available in several sizes placed externally with percutaneous blood-containing silicone cannulae, connected to the atria, left ventricular (LV) apex and the great vessels implanted within the chest. The stationary drive system (IKUS) is utilized for all pumps except when driving pressures $>250 \mathrm{mmHg}$ is required. A mobile driver is used in special conditions. Since November 2019, a new mobile EXCOR Active System designed for small children has been launched.

$\mathrm{EXCOR}^{\circledR}$ is the only one available worldwide, at least for infants and small children.

\section{Intracorporeal continuous flow VAD}

\section{HeartWare ${ }^{\circledR}$ HVAD System (Framingham, MA, USA)}

The HeartWare ${ }^{\circledR}$ ventricular assist device is made up of a miniaturized centrifugal continuous flow HVAD pump with a hybrid magnetic, hydrodynamic impeller suspension without mechanical contact sites. It is thin $(4.2 \mathrm{~mm})$, with flexible driveline and fatigue-resistant cables, implanted within the pericardium minus a pump pocket. It is indicated for implantation in $\geq 25 \mathrm{~kg}$ patients in order to pump a minimum of $2 \mathrm{~L} / \mathrm{min}$ and obviate running an "empty pump".

This device is mainly indicated to support patients with end-stage HF to bridge them to heart transplantation. It is approved for use in the European Union in 2009 and in Australia in 2011.

\section{Infant Jarvik 2015 (Jarvik Heart Inc., New York USA)}

The Infant Jarvik 2015 is an implantable continuous flow VAD particularly intended for small children. The pump bears 2 circular-arc impeller blades, a set of stator blades, and 2 ceramic cone bearings (3). It is FDA-approved for use only in children with a body weight of $>8 \mathrm{~kg}(3,4)$.
Currently, the device has been implanted in 7 children (4 as compassionate use and 3 included in the PumpKIN trial: bridge to transplantation in 3 , explanted in 1 who recovered, 2 for biventricular support and 1 death) in the USA (5).

\section{Implantation: indications, timing, pumps, surgical strategies and postoperative management}

Timing of instituting support with a VAD is crucial to guarantee optimal outcomes in post-implantation management, i.e., decrease incidence of bleeding events or the need for a right ventricular assist device (RVAD). Our initial experience of implanting the VAD as a rescue support has shown us a decreased recovery rate from the consequences of shock, hence we have modified the timing towards early VAD implantation either before irrevocable organ damage ensues or after a short-term ECMO support to evaluate whether recovery from shock sequelae has taken place (6).

Children with congenital heart disease (CHD) usually present with technically challenging anatomical modifications which may compromise the application of VAD support secondary to these anatomical or physiological aberrations. An in-depth knowledge of these unique features is a definite requirement to ensure successful application of VAD (7).

VAD support are not provided for extremely premature babies, in those weighing less than $2.5 \mathrm{~kg}$, with severe neurological dysfunction and contraindications to anticoagulation, and in those with a constellation of congenital diseases and chromosomal abnormalities with poor prognosis.

Implantation of a left or combined left and right VAD is determined in the surgical theatre. Implanting a left VAD (LVAD) is the primary scheme unless the necessity for a biventricular support has been resolved preoperatively. A right VAD is then implanted when signs of right ventricular (RV) failure refractory to medical therapy ensues and the LVAD fails to maintain the cardiac function after weaning off the heart and lung machine.

Pump size is chosen based on body weight (6). The ideal pump flow in small children is 120 to $150 \mathrm{~mL} / \mathrm{kg}$ and $100 \mathrm{~mL} / \mathrm{kg}$ for bigger ones.

Anticoagulation management is compulsory to ensure post-natal growth of coagulation cascade $(8,9)$ and to negate the risk of thromboembolic complications integral to VADblood interactions $(10,11)$.

Routine daily transthoracic echocardiography (TTE) is 
undertaken to evaluate myocardial function. A prophylactic antibiotic with sufficient anti-staphylococcal scope is administered in the perioperative phases. Regular sterile dressing change around the transcutaneous exits are done. The pumps and cannulas are regularly inspected for presence of thrombus.

\section{The role of VAD in children with heart failure}

VAD support was initially carried out as a bridge to transplantation (BTT). Later on, VAD support has been provided to assess eligibility for OHT. Presently, uncertain eligibility to transplantation does not preclude VAD support. VAD support has evolved not only to be just a bridge but also as an armamentarium to treat HF unresponsive to medical therapy. With the evolution of implantable continuous-flow devices, contraindications may eventually be modified. A thorough knowledge of synchronous complications in sufficient number of population could provide evidence-based judgment on contraindications, which is expected to be provided by the registry for Pediatric Mechanically Assisted Circulatory Support (PediMACS) founded in September 2012 to gather data on those $<19$ years who were supported with VAD (12).

\section{Bridge to beart transplantation}

Application of VADs as BTT acquired favor over the last decade and evolved to be considered a complement to end-stage HF management while waiting for OHT. With appropriate patient selection, the outcome is much improved than with medical management alone and comparable to OHT through stabilization of the functional state and preservation of end-organ performance.

EXCOR $^{\circledR}$ has been implanted in 168 patients since April 1990 in Berlin. Outcomes were serially reported in 34 patients in 1999 [1990-1999] $(13,14)$, in 68 patients in 2004 [1990-2004] (15), and 94 patients in 2011 [1990-2009] (16) and summarized in 122 patients in 2016 [1990-2013] (6) with fairly satisfactory outcomes.

We have reported the first and successful EXCOR ${ }^{\circledR}$ implantation in an 8-year-old boy suffering from a longduration of pressure overload due to coarctation of the aorta and stenosis of the aortic valve with life-threatening tachyarrhythmia which resulted to an end-stage HF. Although he was supported with an adult-sized $50 \mathrm{~mL}$ EXCOR $^{\circledR}$, he recovered swiftly and underwent OHT 7 days later (1). Re-transplantation was performed 14 years after the primary OHT and had lived 21 years after the VAD therapy.

Subsequently, increasing use of $\mathrm{EXCOR}^{\circledR}$ in children with end-stage HF in a BTT mode (15-17) ensued. The longest VAD support time reported was 856 days before undergoing OHT (18).

The first successful application of the $\mathrm{EXCOR}^{\circledR}$ in USA as a BTT was performed by Reitz in 2004 in a 4-month-old baby with acute myocarditis, about whom an article came out in New York Times (19) under the US Humanitarian Device Exemption (20).

In Berlin, 201 children (mean age 10.3 \pm 7.6 , range, 3.7-15.11 years) with end-stage HF underwent OHT from April 1990 until September 2014 (21). EXCOR ${ }^{\circledR}$ was implanted in 78 children (mean age $77.8 \pm 6.0$, range, 2.611.8 years) as BTT. Fourteen patients were $<1$ year old. The etiology of HF included dilated cardiomyopathy (DCMP) $(\mathrm{n}=56)$, fulminant myocarditis $(\mathrm{n}=14)$, end-stage CHD $(\mathrm{n}=5)$, post-cardiotomy ischemic $\mathrm{HF}(\mathrm{n}=2)$ and tumor $(\mathrm{n}=1)$, with 2 having an extremely high pulmonary vascular resistance (PVR), 1 had a previous OHT 10 years earlier and 2 with toxicity-induced cardiomyopathy. Mean VAD support time was $133.37 \pm 191.6$ (range, $1-856$ ) days before OHT. Mean duration of follow-up is $10.3 \pm 7.6$ years (21). Cumulative survival rates of these patients were: $93.6 \%$ (30 days), $84.6 \%$ (1 year) $79.1 \%$ ( 5 years), $63.8 \%$ (10 years), 61.6\% (15 years) and $52.1 \%$ (20 years) (21).

We found no significant difference in post-transplantation outcomes in VAD-supported and in primarily transplanted (without VAD support) patients (22) similar to the findings of Eghtesady et al. (23). Neither age at VAD implantation and gender nor etiology of HF, type of VAD system and number of ventricles supported influence the long-term post-transplant survival. Whether it was the left ventricle or both ventricles supported did not influence the long-term outcome of transplantation. It was then clearly illustrated that VADs have indeed a special role as BTT.

Numerous reports (24-31) validated that regardless of the primary etiology of HF, VAD support to preserve end-organ function, while waiting for an organ donor, successfully bridge HF patients to OHT. This also hold true in children with tumor-associated toxicity to allow them to attain a level of transplant eligibility (21).

Morales et al. (32) reported their experience in 73 pediatric patients in 17 centers in USA who were implanted with $\mathrm{EXCOR}^{\circledR}$ showing its effectiveness $(77 \%)$ as a BTT compared to the $39-64 \%$ success rate with ECMO as a support prior to transplantation (33-35). 


\section{Bridge to myocardial recovery}

\section{Indications for weaning and VAD explantation}

Our long-term experience with VAD revealed that restitution of sufficient circulation may lead to functional recovery of already impaired organs (6).

No infant was discharged home after VAD support until 1998 (15). Since then, several improvements in VAD configuration, postoperative care and earlier VAD support prior to onset of profound shock have been introduced.

The concept of weaning off VAD support has begun in 1999 in Berlin. For the first time, myocardium recovered after VAD support in 5 patients with dilated cardiomyopathy, with eventual VAD explantation reported by Müller et al. (36) and Hetzer et al. (37) in 1999. A sustained long-term myocardial recovery was substantiated by complementary evidences from their clinical experiences $(38,39)$. In children, myocardial recovery with VAD support and post-weaning outcome data is barely known. However, in 1998 and 1999, the Berlin group championed the possibility of myocardial recovery after VAD support in children $(2,31,40)$.

After VAD implantation, routine daily TTE is carried out. Weaning is deemed possible when progressive improvement of cardiac function is demonstrated based on echocardiographic parameters. The final judgment of VAD explantation is done in the surgical theatre, by reduction of pump flow and monitoring of blood pressure and enddiastolic ventricular volume. When the set of explantation parameters are met, weaning is carried out by a 20 -minute pump stoppage (6).

\section{Outcome of weaning and VAD explantation}

Hetzer et al. (6) reported the results in 122 children (median age 8.6 years; range, 3 days -17 years; $>1$ year old, $n=35$ ) with advanced HF (cardiomyopathy, $\mathrm{n}=56$; fulminant myocarditis, $\mathrm{n}=17$; end-stage $\mathrm{CHD}, \mathrm{n}=18$; post-cardiotomy HF after CHD correction, $n=28$ and graft failure, $n=3$ ), either dependent from inotropic drugs or replaced from ECMO support or had post-cardiotomy low-output syndrome, on whom EXCOR ${ }^{\circledR}$ implantation was carried out between 1990 and 2013. Before EXCOR ${ }^{\circledR}$ implantation, 24 underwent CPR while 15 were brought to the operating theater under resuscitation.

Successful weaning was performed in 18 patients, amid 9 patients (1-6 years old) with myocarditis recovered, showing prompt restoration of myocardial activity, hence, subsequent device explantation within 10-42 days. They had a satisfactory recovery and currently are energetic school children. Follow-up echocardiography (range 4-10 years post-VAD explantation) revealed normal cardiac function and no HF recurrence.

Myocardial recovery was demonstrated in 2 children (ages 0.3 and 14 years) with DCMP on days 17 and 125, respectively. This was also confirmed in $5(0.3-4$ years old) with end-stage CHD after 6-60 days as well as in one after 63 days post-EXCOR ${ }^{\circledR}$ implantation. The EXCOR ${ }^{\circledR}$ was likewise implanted in a post-heart transplant 16-yearold boy who exhibited allograft failure. Recovery of the myocardium was demonstrated on the 76th day.

Recently, we updated the outcome in 21 patients (median age 5.8 years) on whom VAD was implanted from January 1990 to May 2016 and successfully weaned based on an echocardiographic protocol developed in 2005. Factors which could influence recovery were demonstrated to be age of less than 2 years and histologically-documented myocarditis (41).

\section{Bridge to transplantability}

Based on our experience, we have acknowledged that extended time of VAD therapy in patients undergoing cancer treatment with toxicity-induced HF allow them to be transplant eligible once a lengthy tumor-free period is established. Moreover, transplant eligibility is attained by patients with elevated PVR refractory to vasodilators which normalized after prolonged VAD support (6). It is theorized that LV unloading lowers the left atrial pressure, hence, decreasing the pulmonary artery pressure, as authenticated in adult studies (42). Sufficient reduction of PVR may be anticipated within 3-6 months of VAD support, thus patients may be eligible for OHT.

\section{Adult ventricular assist devices implanted in children}

\section{HeartWare $^{\circledR}$ HVAD}

Implantation of HeartWare ${ }^{\circledR}$ HVAD) is indicated in children with a body surface area (BSA) $>0.7 \mathrm{~m}^{2}$ or weighing $>25 \mathrm{~kg}$ if they are inotrope-dependent and utilized as a BTT.

\section{Outcome of implantation}

The first implantation of the HeartWare ${ }^{\circledR}$ HVAD in 7 children (6-16 years old, 17-79 kg, BSA 0.7-2.0 m²) was performed in Berlin in 2011 (43). Six had DCMP and 1 had 
end-stage failure of Fontan physiology. A successful OHT was carried out in 6 after 138 days of VAD support and 1 is presently on VAD support for 246 days.

In the USA, the first HeartWare ${ }^{\circledR}$ HVAD implantation was in 2012 on a 9-year-old girl in cardiogenic shock with cardiomyopathy and an embolic stroke. Eventually OHT was performed after 60 days of support (44).

A multicenter study was conducted on 13 children (median age 8.1 years, median BSA $0.8 \mathrm{~m}^{2}$; myocarditis $=9$, CHD $=3$, post-transplantation $=1$ ) on whom HeartWare ${ }^{\circledR}$ HVAD was implanted between January 2010 and May 2015 (45). Hemorrhage, kidney insufficiency, the requirement for mechanical ventilation for 36 days and pump thrombosis were the most common adverse events. Bleeding occurred early post-implantation (46) but incidence is decreased compared to those supported with pulsatile VADs (47).

\section{Issues and concerns in pediatric VAD}

\section{Anticoagulation}

Anticoagulation management continues to be a significant concern. Coating the device with heparin has not resolved the issue. Pump thrombosis remains the primary indication for pump exchange. Increased thromboembolism and hemorrhage still exist. Furthermore, it poses difficulty to attain a satisfactory anticoagulation in infants due to the intrinsic factors associated with maturation, handling of medications and repetitive blood testing (6).

An antithrombotic therapy guideline (Edmonton Protocol) was introduced during the US EXCOR ${ }^{\circledR}$ approval investigation $(47,48)$. This protocol evolved to be the advocated antithrombotic approach for $\mathrm{EXCOR}^{\circledR}$ recipients (49). However, the major occurrence of ischemic neurologic events observed has become an impetus to modify the guideline (50). Rosenthal et al. (51) reported a lower stroke with the Stanford triple anti-thrombotic scheme (aspirin, clopidogrel and dipyridamole) compared to dual antiplatelet therapy recommended in the Edmonton Protocol. Furthermore, there have been several reports $(52,53)$ showing absence of thrombus with the use of Bivalirudin.

\section{Pump thrombosis and neurologic events}

We have encountered an increased occurrence of thrombus/fibrin formation in the pumps necessitating pump exchanges. These may have been secondary to a technical factor, i.e., cannulation of the left atrium which is recognized a contributory to stroke. The $\mathrm{EXCOR}^{\circledR}$ pumps are equipped with the less thrombogenic polyurethane valves and through the transparency of chambers, one is able to regulate filling and emptying as well as observation of thrombus. Nonetheless, thromboembolic episodes and exchanging of pumps occur even with meticulous compliance to the anticoagulation regimen (6).

\section{Bleeding}

The hematologic complications which are mostly mediastinal bleeding typically happen in the early postimplantation period (6).

\section{Challenges}

\section{Allosensitization}

Allograft rejection is associated to sensitization post-VAD therapy $(54,55)$. Allosensitization is one of the key elements in management regimen of patients supported with VAD as a BTT, hence desensitization is essential $(21,56,57)$. Adults on VAD support have been recognized to develop HLA antibodies (58). VAD instigate multifactorial dysregulatory activities secondary to circulating anti-HLA class I and II antibodies, hence, patients on LVAD support are predisposed to repetitive cross-matching, increased waiting time to transplant and amplified risk of allograft rejection after transplant (59). In adults, it has been hypothesized that the structure of the interior VAD surface or the development of de novo intima post-VAD elicited an atypical activationinduced T-cell apoptosis and B-cell hyperreactivity (60). In children, outcome is dependent on sensitization level and on the juvenile immunology. In this context we routinely monitor panel reactive antibody during VAD therapy and post-transplantation. Likewise, an aggressive immunosuppression regimen is absolutely required to obviate early rejection in sensitized children $(6,21)$.

\section{Single ventricles}

VAD implantation in children with single ventricle physiology after palliative surgery has been challenging with regards to positioning the inflow and outflow cannulae. Prêtre et al. reported positioning the univentricular assist device on the right side for a failed Fontan procedure (61). A biventricular assist device was implanted by Nathan et al. (62) on a patient with a failed cavopulmonary anastomosis in 
a Norwood-Fontan pathway. An extracorporeal VAD was implanted in the $L V$ apex after a failing conversion to a total or partial cavopulmonary connection by other teams $(63,64)$. In these circumstances, the primary issue was a failed driving ventricle postoperatively. The decrease in venous pressure, has a major influence in a Fontan physiology but there is a circumscribed advantage in failing pulmonary circulation, i.e., the development of PVR, usually increased in failing Fontan, is improbable to be quantified as well as a low chance to save patients presenting in emergent conditions (65).

\section{Perspectives}

There is a great need for technological innovation in VAD in children. The system must be: (I) miniaturized with components of high durability, (II) infection-free power resource (III) easy to be implanted and exchanged, (IV) with less or absence of predisposition to development of thrombus by redesigning the pump internal configuration, (V) in a continuous-flow mode, (VI) adjustment of pump function according to physiological demand, (VII) safety features of local and remote control, and (VIII) with features allowing an easy and intuitive patients'/parents' system management.

Moreover, VAD systems tailored to the special anatomical and physiological conditions in patients with complex congenital cardiac anomalies are non-existent and this must be addressed.

Some other concepts in technology and design may eventually evolve, though with obstacles, since technical advancements, clinical studies and approval require approximately $>$ years, hence is futuristic. Financial support from government and agencies are likewise difficult to obtain. The latest development of Jarvik 2015 is anticipated to be highly reliable, albeit still controversial. Small, implantable adult VAD intended for use in young patients is desired and could become the standard. As of now, the present VADs could be altered to be applicable to unique ventricular anatomies.

Nevertheless, several studies as of to date have demonstrated that VAD excellently support children until $\mathrm{OHT}$ and could allow recovery of the myocardium. These evidences emphasize the need for improvement of the VADs to fine-tune ramifications in this special group.

\section{Acknowledgments}

Funding: None.

\section{Footnote}

Provenance and Peer Review: This article was commissioned by the editorial office, Cardiovascular Diagnosis and Therapy for the series "Heart Failure in the Young and Old: Insights into Various Therapies". The article has undergone external peer review.

Conflicts of Interest: All authors have completed the ICMJE uniform disclosure forms (available at http://dx.doi. org/10.21037/cdt-20-282). The series "Heart Failure in the Young and Old: Insights into Various Therapies" was commissioned by the editorial office without any funding or sponsorship. RH served as the unpaid Guest Editor of the series and serves as an unpaid editorial board member of Cardiovascular Diagnosis and Therapy from July 2019 to Jun 2021. The authors have no other conflicts of interest to declare.

Ethical Statement: All authors have worked on this paper and are accountable for all aspects of the work in ensuring that questions related to the accuracy or integrity of any part of the work are appropriately investigated and resolved.

Open Access Statement: This is an Open Access article distributed in accordance with the Creative Commons Attribution-NonCommercial-NoDerivs 4.0 International License (CC BY-NC-ND 4.0), which permits the noncommercial replication and distribution of the article with the strict proviso that no changes or edits are made and the original work is properly cited (including links to both the formal publication through the relevant DOI and the license). See: https://creativecommons.org/licenses/by-nc-nd/4.0/.

\section{References}

1. Warnecke H, Berdjis F, Hennig E, et al. Mechanical left ventricular support as a bridge to cardiac transplantation in childhood. Eur J Cardiothorac Surg 1991;5:330-3.

2. Hetzer R, Loebe M, Potapov EV, et al. Circulatory support with pneumatic paracorporeal ventricular assist device in infants and children. Ann Thorac Surg 1998;66:1498-506.

3. Di Molfetta A, Zielinski K, Ferrari G, et al. Is the new infant Jarvik 2015 suitable for patients $<8 \mathrm{~kg}$ ? in vitro study using a hybrid simulator. Artif Organs 2019;43:E1-8.

4. Burki S, Adachi I. Pediatric ventricular assist devices: current challenges and future prospects. Vasc Health Risk 
Manag 2017;13:177-85.

5. Adachi I, Spinner JA, Tunuguntla HP, et al. The miniaturized pediatric continuous- flow device: A successful bridge to heart transplant. J Heart Lung Transplant 2019;38:789-93.

6. Hetzer R, Kaufmann F, Delmo Walter EM. Paediatric mechanical circulatory support with Berlin Heart EXCOR: development and outcome of a 23-year experience. Eur J Cardiothorac Surg 2016;50:203-10.

7. del Nido PJ, Duncan BW, Mayer JE Jr, et al. Left ventricular assist device improves survival in children with left ventricular dysfunction after repair of anomalous origin of the left coronary artery from the pulmonary artery. Ann Thorac Surg 1999;67:169-72.

8. Baldwin ACW, Sandoval E, Letsou GV, et al. Surgical approach to continuous-flow left ventricular assist device explantation: a comparison of outcomes. J Thorac Cardiovasc Surg 2016;151:192-8.

9. Awad M, Czer LS, Soliman C, et al. Prevalence of warfarin genotype polymorphisms in patients with mechanical circulatory support. ASAIO J 2015;61:391-6.

10. Fraser KH, Zhang T, Taskin ME, et al. A quantitative comparison of mechanical blood damage parameters in rotary ventricular assist devices: shear stress, exposure time and hemolysis index. J Biomech Eng 2012;134:081002.

11. Yu X, Larsen B, Rutledge J, et al. The profile of the systemic inflammatory response in children undergoing ventricular assist device support. Interact Cardiovasc Thorac Surg 2012;15:426-31.

12. Adachi I, Buri S, Zafar F, et al. Pediatric ventricular assist devices. J Thorac Dis 2015;7:2194-2202.

13. Hetzer R, Loebe M, Alexi-Meskishvili V, et al. Pulsatile pediatric assist devices: current results for bridge to transplantation. Semin Thorac Cardiovasc Surg Pediatr Card Surg Annu 1999;2:157-76.

14. Hetzer R, Potapov EV, Stiller B, et al. Improvement in survival after mechanical circulatory support with pneumatic pulsatile ventricular assist devices in pediatric patients. Ann Thorac Surg 2006;82:917-24.

15. Hetzer R, Alexi-Meskishvili V, Weng Y, et al. Mechanical cardiac support in the young with the Berlin Heart EXCOR pulsatile ventricular assist device: 15 years' experience. Semin Thorac Cardiovasc Surg Pediatr Card Surg Annu 2006;9:99-108.

16. Hetzer R, Potapov E, Alexi-Meskishvili V, et al. Singlecenter experience with treatment of cardiogenic shock in children bypediatric ventricular assist devices. J Thorac Cardiovasc Surg 2011;141:616-23.
17. Hetzer R, Stiller B. Technology insight: use of ventricular assist devices in children. Nat Clin Pract Cardiovasc Med 2006;3:377-86.

18. Hetzer R, Miera O, Photiadis J, et al. Heart transplantation after longest support with ventricular assist devices. Ann Thorac Surg 2014;98:1814-5.

19. Grady D. Tubes, Pump and Fragile Hope Keep a Baby's Heart Beating. New York, NY: New York Times 2004, 22 August 2004; Section 1.

20. Malaisrie SC, Pelletier MP, Yun JJ, et al. Pneumatic paracorporeal ventricular assist device in infants and children: initial Stanford experience. J Heart Lung Transplant 2008;27:173-7.

21. Hetzer R, Javier MFDM, Delmo Walter EM. Role of paediatric assist device in bridge to transplant. Ann Cardiothorac Surg 2018;7:82-98.

22. Hetzer R, Weng Y, Delmo Walter EM. State of the art in paediatric heart transplantation: The Berlin experience Eur J Cardiothorac Surg 2013;43:258-67.

23. Eghtesady P, Almond CS, Tjossem C, et al. Posttransplant outcomes of children bridged to transplant with the Berlin Heart EXCOR Pediatric ventricular assist device. Circulation 2013;128:S24-31.

24. Sharma MS, Webber SA, Morell VO, et al. Ventricular assist device support in children and adolescents as a bridge to heart transplantation. Ann Thorac Surg 2006;82:926-32.

25. Davies RR, Haldeman S, McCulloch MA, et al. Ventricular assist devices as a bridge-to-transplant improve early posttransplant outcomes in children. J Heart Lung Transplant 2014;33:704-12.

26. Chen JM, Richmond ME, Charette K, et al. A decade of pediatric mechanical circulatory support before and after cardiac transplantation. J Thorac Cardiovasc Surg 2012;143:344-51.

27. Miller JR, Eghtesady P. Ventricular assist device use in congenital heart disease with a comparison to heart transplant. J Comp Eff Res 2014;3:533-46.

28. Kindel SJ, Everitt MD. A contemporary review of paediatric heart transplantation and mechanical circulatory support. Cardiol Young 2016;26:851-9.

29. Lorts A, Blume ED. Pediatric mechanical circulatory support: available devices and outcomes as bridgeto-transplant therapy. Curr Opin Organ Transplant 2015;20:557-61.

30. Wehman B, Stafford KA, Bittle GJ, et al. Modern outcomes of mechanical circulatory support as a bridge to pediatric heart transplantation. Ann Thorac Surg 
2016;101:2321-7.

31. De Rita F, Hasan A, Haynes S, et al. Outcome of mechanical cardiac support in children using more than one modality as a bridge to heart transplantation. Eur J Cardiothorac Surg 2015;48:917-22; discussion 922.

32. Morales DL, Almond CS, Jaquiss RD, et al. Bridging children of all sizes to cardiac transplantation: the initial multicenter North American experience with the Berlin Heart EXCOR ventricular assist device. J Heart Lung Transplant 2011;30:1-8.

33. Kirshbom PM, Bridges ND, Myung RJ, et al. Use of extracorporeal membrane oxygenation in pediatric thoracic organ transplantation. J Thorac Cardiovasc Surg 2002;123:130-6.

34. Gajarski RJ, Mosca RS, Ohye RG, et al. Use of extracorporeal life support as a bridge to pediatric cardiac transplantation. J Heart Lung Transplant 2003;22:28-34.

35. Fiser WP, Yetman AT, Gunselman RJ, et al. Pediatric arteriovenous extracorporeal membrane oxygenation (ECMO) as a bridge to cardiac transplantation. J Heart Lung Transplant 2003;22:770-7.

36. Müller J, Wallukat G, Weng YG, et al. Weaning from mechanical cardiac support in patients with idiopathic dilated cardiomyopathy. Circulation 1997;96:542-9.

37. Hetzer R, Müller J, Weng Y, et al. Cardiac recovery in dilated cardiomyopathy by unloading with a left ventricular assist device. Ann Thorac Surg 1999;68:742-9.

38. Dandel M, Knosalla C, Hetzer R. Contribution of ventricular assist devices to the recovery of failing hearts: a review and the Berlin Heart Center Experience. Eur J Heart Fail 2014;16:248-63.

39. Dandel M, Hetzer R. Myocardial recovery during mechanical circulatory support: long-term outcome and elective ventricular assist device implantation to promote recovery as a treatment goal. Heart Lung Vessel 2015;7:289-96.

40. Stiller B, Dähnert I, Weng YG, et al. Children may survive severe myocarditis with prolonged use of biventricular assist devices. Heart 1999;82:237-40.

41. Miera O, Germann M, Cho MY, et al. Bridge to recovery in children on ventricular assist devices-protocol, predictors of recovery, and long-term follow-up. J Heart Lung Transplant 2018;37:1459-66.

42. Potapov E, Schweiger M, Lehmkuhl E, et al. Gender differences during mechanical circulatory support. ASAIO J 2012;58:320-5.

43. Miera O, Potapov EV, Redlin M, et al. First experiences with the HeartWare ventricular assist system in children. Ann Thorac Surg 2011;91:1256-60.

44. Kirklin JK, Pearce FB, Pamboukian SV, et al. Implantation of the HeartWare HVAD in a child after a recent thromboembolic stroke. Ann Thorac Surg 2012;93:977-8.

45. Miera O, Kirk R, Buchholz H, et al. A multicenter study of the HeartWare ventricular assist device in small children. J Heart Lung Transplant 2016;35:679-81.

46. Cabrera AG, Sundareswaran KS, Samayoa AX, et al. Outcomes of pediatric patients supported by the HeartMate II left ventricular assist device in the United States. J Heart Lung Transplant 2013;32:1107-13.

47. Almond CS, Buchholz H, Massicotte P, et al. Berlin Heart EXCOR pediatric ventricular assist device investigational device exemption study: study design and rationale. Am Heart J 2011;162:425-6.

48. Fraser CD Jr, Jaquiss ROB, Rosenthal DN, et al. Prospective trial of a pediatric ventricular assist device. $\mathrm{N}$ Engl J Med 2012;367:532-41.

49. Steiner ME, Bomgaars LR, Massicotte MP, et al. Antithrombotic therapy in a prospective trial of a pediatric ventricular assist device. ASAIO J 2016;62:719-27.

50. Almond CS, Morales DL, Blackstone EH, et al. Berlin Heart EXCOR pediatric ventricular assist device for bridge to heart transplantation in US children. Circulation 2013;127:1702-11.

51. Rosenthal DN, Lancaster CA, McElhinney DB, et al. Impact of a modified anti-thrombotic guideline on stroke in children supported with a pediatric ventricular assist device. J Heart Lung Transplant 2017;36:1250-7.

52. Medar SS, Hsu DT, Lamour JM, et al. Use of bivalirudin as a primary anticoagulant in a child during Berlin Heart EXCOR ventricular assist device support. Perfusion 2020;35:172-6.

53. Chetan D, Buchholz H, Bauman M, et al. Successful treatment of pediatric ventricular assist device thrombosis. ASAIO J 2018;64:e28-32.

54. Meeteren JV, Maltais S, Dunlay SM, et al. A multiinstitutional outcome analysis of patients undergoing left ventricular assist device implantation stratified by sex and race. J Heart Lung Transplant 2017;36:64-70.

55. Malickaite R, Rucinskas K, Staneviciene A, et al. Sensitisation and post-transplant course after the implantation of ventricular assist device. Interact Cardiovasc Thorac Surg 2009;8:339-42; discussion 342.

56. Arnaoutakis GJ, George TJ, Kilic A, et al. Effect of sensitization in US heart transplant recipients bridged with a ventricular assist device: update in a modern cohort. J 
Thorac Cardiovasc Surg 2011;142:1236-45, 1245.e1.

57. Hummel M, Döcke WD, Friedel N, et al. Monitoring of the cellular immune system in patients with biventricular assist devices awaiting cardiac transplantation. Clin Transplant 1994;8:59-66.

58. Hummel M, Czerlinski S, Friedel N, et al. Interleukin-6 and interleukin- 8 concentrations as predictors of outcome in ventricular assist device patients before heart transplantation. Crit Care Med 1994;22:448-54.

59. O'Connor MJ, Menteer J, Chrisant MR, et al. Ventricular assist device-associated anti-human leukocyte antigen antibody sensitization in pediatric patients bridged to heart transplantation. J Heart Lung Transplant 2010;29:109-16.

60. Schuster M, Kocher A, John R, et al. B cell activation and allosensitization after left ventricular assist device implantation is due to $\mathrm{T}$ cell activation and CD40 ligand expression. Hum Immunol 2002;63:211-20.

Cite this article as: Javier Delmo EM, Javier MFDM, Hetzer $\mathrm{R}$. The role of ventricular assist device in children. Cardiovasc Diagn Ther 2021;11(1):193-201. doi: 10.21037/cdt-20-282
61. Prêtre R, Haussler A, Bettex D, et al. Right-sided univentricular cardiac assistance in a failing Fontan circulation. Ann Thorac Surg 2008;86:1018-20.

62. Nathan M, Baird C, Fynn-Thompson F, et al. Successful implantation of a Berlin heart biventricular assist device in a failing single ventricle. J Thorac Cardiovasc Surg 2006;131:1407-8.

63. Frazier OH, Gregoric ID, Messner GN. Total circulatory support with an LVAD in an adolescent with a previous Fontan procedure. Tex Heart Inst J 2005;32:402-4.

64. Newcomb AE, Negri JC, Brizard CP, et al. Successful left ventricular assist device bridge to transplantation after failure of a Fontan revision. J Heart Lung Transplant 2006;25:365-7.

65. Khambadkone S, Li J, de Leval MR, et al. Basal pulmonary vascular resistance and nitric oxide responsiveness late after Fontan-type operation. Circulation 2003;107:3204-8. 